\title{
Identificação sorológica e relação filogenética de Salmonella spp. de origem suína ${ }^{1}$
}

\author{
Roberta T. Melo ${ }^{2,3^{*}}$, Adélia R. Guimarães ${ }^{2}$, Eliane P. Mendonça ${ }^{2,3}$, Letícia R. Coelho ${ }^{2,3}$, \\ Guilherme P. Monteiro ${ }^{2,3}$, Belchiolina B. Fonseca ${ }^{4}$ e Daise A. Rossi ${ }^{2}$
}

\begin{abstract}
Melo R.T., Guimarães A.R., Mendonça E.P., Coelho L R., Monteiro G.P., Fonseca B.B. \& Rossi D.A. 2011. [Serological identification and phylogenetic relationship of Salmonella spp. pig origin.] Identificação sorológica e relação filogenética de Salmonella spp. de origem suína. Pesquisa Veterinária Brasileira 31(12):1039-1044. Laboratório de Biotecnologia Animal Aplicada, Faculdade de Medicina Veterinária, Universidade Federal de Uberlândia, Rua Ceará s/n, Bloco 2D, sala 43, Bairro Umuarama, Uberlândia, MG 38402-018, Brazil. E-mail: roberta-melo@hotmail.com

Salmonella spp. is an important zoonotic pathogen that can spread along the production chain of swines. The objective was to evaluate the incidence of Salmonella spp. in feces of swines in termination phase in the farm, in the pre-slaughter and environmental samples, identify the serotypes and establish a phylogenetic relationship among the isolates. Three collections were done in different batches of pigs housed in the termination pen and in the same animals after transport to the slaughterhouse totaling 90 plots and 9 environmental samples. The transport does not influenced the percentage of isolation of the microorganism ( $p>0.05)$. Of the total of 99 samples, 50 (50.5\%) were identified as Salmonella spp., and was identified a variety of serovars: Agona (30\%), Typhimurium (26\%), Minnesota (24\%), Infantis (18\%) and Panama (2\%). Dendrograms showed homology among isolates of different serovars grouped into clusters. The similarity was independent of the local of isolation, indicating the presence of several clones. The main sources of infection were cross-contamination between animals and environment and the consumption of contaminated feed. The diversity of strains and homology among the isolates indicates a common origin, demonstrating a need for monitoring of zoonotic bacterias and the deployment of more effective control measures for Salmonella spp. in swines.
\end{abstract}

INDEX TERMS: Salmonellosis, serotyping, RAPD.

RESUMO.- Salmonella spp. é um importante patógeno zoonótico que pode ser disseminado ao longo da cadeia produtiva de suínos. Objetivou-se avaliar a incidência de Salmonella spp. em fezes de suínos de terminação na granja, no pré-abate e amostras ambientais, identificar os sorovares e

\footnotetext{
${ }^{1}$ Recebido em 3 de fevereiro de 2011.

Aceito para publicação em 19 de junho de 2011.

${ }^{2}$ Laboratório de Biotecnologia Animal Aplicada, Faculdade de Medicina Veterinária, Universidade Federal de Uberlândia (UFU), Rua Ceará s/n, Bloco 2D, sala 43, Bairro Umuarama, Uberlândia, MG 38402-018, Brasil *Autor para correspondência: roberta-melo@hotmail.com

${ }^{3}$ Programa de Pós-Graduação em Ciências Veterinárias, Universidade Federal de Uberlândia (UFU), Rua Ceará s/n, Bloco 2T , Bairro Umuarama, Uberlândia, MG 38400-902.

${ }^{4}$ Programa de Pós-Graduação em Imunologia e Parasitologia Aplicadas, UFU, Av. Pará 1720, Bloco 4C, sala 218, Bairro Umuarama, Uberlândia, MG 38400-902.
}

estabelecer a relação filogenética entre os isolados. Foram realizadas três coletas em lotes diferentes de suínos alojados na granja de terminação e nos mesmos animais após o transporte ao frigorífico totalizando 90 parcelas e 9 amostras ambientais. 0 transporte não influenciou na porcentagem de isolamento do microrganismo $(p>0,05)$. Das 99 amostras, 50 (50,5\%) foram identificados como Salmonella spp., sendo identificado uma multiplicidade de sorovares: Agona (30\%), Typhimurium (26\%), Minnesota (24\%), Infantis (18\%) e Panama (2\%). Os dendrogramas demonstraram homologia entre isolados dos diferentes sorovares agrupados em clusters. A similaridade foi independente do local de isolamento indicando a presença de vários clones. As principais fontes de infecção determinadas foram a contaminação cruzada entre animais e ambiente e o consumo de ração contaminada. A diversidade de sorovares e a ho- 
mologia entre eles indicam origem comum, demonstrando necessidade de monitoramento de bactérias zoonóticas e de implantação de medidas de controle mais eficazes para Salmonella spp. em suínos.

TERMOS DE INDEXAÇÃO: Salmonelose, sorotipagem, RAPD.

\section{INTRODUÇÃO}

A salmonelose é uma das principais causas de gastroenterites em humanos veiculada por alimentos em todo o mundo. Trata-se de um importante problema de saúde pública tanto em países industrializados como em desenvolvimento (EFSA 2009, EFSA 2010, Loureiro et al. 2010).

Produtos de origem suína merecem atenção como fontes potenciais de salmoneloses que acometem humanos. A preocupação aumentou depois que surtos de infecção alimentar ocorridos na Dinamarca tiveram sua origem associada ao consumo destes produtos (Fedorka-Cray 1996). Mais recentemente, Hill et al. (2008) relataram que de 1\% a $10 \%$ das salmoneloses humanas são atribuídas ao consumo de carne suína e que $17 \%$ dos suínos em idade de abate podem estar infectados por Salmonella spp. e 4\% deles excretando o microrganismo nas fezes.

A maioria dos sorovares de Salmonella spp. que infectam suínos não causa doença clínica nesses animais. Todavia, mesmo animais aparentemente saudáveis podem excretar a bactéria de forma intermitente pelas fezes e, assim, contaminar o ambiente e outros animais (Castagna, Schwarz \& Cardoso 2004). No caso de suínos, esta situação também pode ocorrer durante o transporte dos animais (Katja \& Henrik 2003).

Segundo Rostagno et al. (2003) é amplamente aceito que os animais infectados com Salmonella spp. são as maiores fontes de infecção para outros animais e seres humanos. Assim, é importante o monitoramento constante com identificação dos sorovares e estabelecimento da relação epidemiológica desses ao longo da cadeia de produção (EFSA 2008).

A epidemiologia da infecção por Salmonella spp. em suínos é complexa, apresentando múltiplos fatores determinantes na transmissão deste microrganismo. Primariamente, as fontes de infecção podem ser animais pertencentes ao próprio grupo, animais de outros grupos da mesma granja ou fatores externos como a ração, os cuidados de manipulação pelos empregados ou o próprio ambiente da granja ou frigorífico (Van der Gaag et al. 2004).

Ao longo da cadeia de produção é possível observar a amplificação do problema, geralmente pela rápida transmissão desta bactéria a animais não infect ados. Diante disso, objetivou-se conhecer as espécies, os sorotipos e a relação filogenética entre cepas de Salmonella isoladas de amostras ambientais e de fezes de suínos, estabelecendo possíveis vias de infecção, e ainda, se o estresse a que os animais são submetidos durante o transporte influencia na excreção deste microrganismo.

\section{MATERIAL E MÉTODOS}

O estudo foi realizado em uma granja de terminação de suínos e em um frigorífico sob inspeção municipal localizados na região do Triângulo Mineiro, MG. Foram analisadas 90 amostras de fe- zes coletadas por meio de swab retal, seis swabs de arrasto do ambiente dos animais e três amostras de ração, totalizando 99 parcelas.

As coletas foram realizadas nos animais na granja de terminação e nestes mesmos animais após o transporte ao frigorífico e já alojados na pocilga de espera. Foram amostrados em períodos distintos três lotes subsequentes de suínos em fase de terminação (idade de 138-140 dias) e com peso médio de $90 \mathrm{Kg}$. Em cada coleta eram incluídos quinze animais e amostras de ração e swabs de arrasto.

0 processamento e análise das amostras foram realizados no Laboratório de Biotecnologia Animal Aplicada da Universidade Federal de Uberlândia (Labio-UFU) e a caracterização antigênica no Setor de Enterobactérias da Fundação Osvaldo Cruz (Fiocruz) no Rio de Janeiro.

O isolamento e a identificação bioquímica de Salmonella spp. foram realizados individualmente segundo a metodologia descrita por Michael et al. (2003). A identificação sorológica do gênero foi realizada com o antissoro polivalente somático “ 0 " (Biobrás ${ }^{\circledR}$ ). A caracterização preliminar dos grupos com os antissoros monovalentes somáticos $\mathrm{B}, \mathrm{C}$ e D $\left(\mathrm{Biorad}^{\circledR}\right)$ foi realizado pela metodologia de aglutinação em placa conforme protocolo recomendado no PNSA - Programa Nacional de Sanidade Avícola do Ministério da Agricultura, Pecuária e Abastecimento (Brasil 1994). Os isolados puros em ágar nutriente foram submetidos à sorotipificação definitiva na Fiocruz.

As cepas foram submetidas à análise gênica por RAPD (Random Amplified Polymorphic DNA). 0 protocolo utilizado foi o descrito por Oliveira et al. (2007). Para análise dos resultados foi feita comparação das cepas antigenicamente identificadas como pertencentes ao mesmo sorovar.

O DNA foi extraído por lise térmica de um volume de $5 \mathrm{~mL}$ de um cultivo de 24 horas em BHI (brain heart infusion) (Difco ${ }^{\circledR}$ ) e centrifugado a $12.000 \mathrm{~g}$ por dois minutos; o sobrenadante foi desprezado. Foram adicionados $800 \mu \mathrm{L}$ de água ultrapura ao pellet $\mathrm{e}$ centrifugado novamente a $12.000 \mathrm{~g}$ por dois minutos. 0 sobrenadante foi descartado e o pellet ressuspendido em $200 \mu \mathrm{L}$ de água ultrapura e aquecido a $95^{\circ} \mathrm{C}$ por 10 minutos, resfriado e, por fim, congelado para posterior utilização. A quantificação foi realizada em espectrofotômetro (Nanodrop®).

Foi utilizado o primer P1254 (5' CCGCAGCCAA 3'). O volume final para a reação de amplificação foi de $25 \mu \mathrm{L}$, composto por: 100 mmol Tris $\mathrm{HCl}, 750 \mathrm{mmol} \mathrm{KCl}$ pH 8 do tampão, $10 \mathrm{mmol}$ dNTPs ( $5 \mathrm{mmol}$ de cada dATP, dCTP, dGTP e dTTP), 50mmol $\mathrm{MgCl} 2,40$ pmol do primer, $1 \mathrm{U}$ de Taq DNA Polymerase $5 \mathrm{U} / \mu \mathrm{L}$ (Invitrogen ${ }^{\circledR}$ ), 15,3 $\mu \mathrm{L}$ de água ultrapura estéril e 30ng de DNA.

A amplificação em termociclador (Eppendorf ${ }^{\circledR}$ ) obedeceu aos seguintes ciclos: um ciclo de $95^{\circ} \mathrm{C}$ por 5 minutos, seguido de $40 \mathrm{ci}$ clos de $95^{\circ} \mathrm{C}$ por 1 minuto, $30^{\circ} \mathrm{C}$ por 1 minuto, $72^{\circ} \mathrm{C}$ for 1 minuto, e extensão final a $72^{\circ} \mathrm{C}$ por 5 minutos. Os produtos amplificados $(5 \mu \mathrm{L})$ foram submetidos à eletroforese em gel de agarose a 1,5\%, utilizando como padrão de peso molecular o marcador de $100 \mathrm{pb}$ (Invitrogen ${ }^{\circledR}$ ). A reação foi realizada em paralelo com a cepa ATCC 13076 de Salmonella Enteritidis e incluiu um controle negativo composto de água ultrapura em substituição ao DNA alvo. Além disso, foram realizadas três repetições a fim de confirmar os padrões das bandas.

Os resultados obtidos com a tipificação antigênica foram tabulados e submetidos à estatística descritiva. Para comparar as diferentes proporções de positividade dos lotes e avaliar a incidência de Salmonella spp. antes e após o transporte foi utilizado o teste de McNemar com significância de 5\% (Ayres 2000). As análises do RAPD foram realizadas utilizando o coeficiente de similaridade de Dice, com tolerância de 1,5\% na comparação da posição de bandas e o dendograma formado com base no método UPGMA 
(Unweighted Pair Group Method with Arithmetic Mean - agrupamento pareado não ponderado baseado na média aritmética) com otimização do gel de $0,80 \%$. Os procedimentos foram realizados com o software BioNumerics.

\section{RESULTADOS E DISCUSSÃO}

No total foram isoladas 50 cepas de Salmonella spp. (Quadro 1). Destas, $25(50,0 \%)$ foram isoladas de fezes e duas $(4,0 \%)$ de ração, ambas na granja de terminação; 22 $(44,0 \%)$ nas fezes dos mesmos animais na pocilga de espera do frigorífico e, neste ambiente, uma $(2,0 \%)$ recuperada por meio de swab de arrasto.

Quadro 1. Salmonella spp. isoladas de suínos, discriminadas por lote, tipo de amostra e local de colheita

\begin{tabular}{|c|c|c|c|c|c|}
\hline Amostra & $\begin{array}{l}\text { Local de } \\
\text { isolamento }\end{array}$ & $1^{\text {o }}$ lote & $2^{\circ}$ lote & 3 o lote & $\begin{array}{l}\text { Total } \\
\mathrm{P}(\%)\end{array}$ \\
\hline $\begin{array}{l}\text { Fezes-Swab } \\
\text { retal }(\mathrm{n}=45)\end{array}$ & $\begin{array}{c}\text { Granja } \\
\text { (terminação) }\end{array}$ & 9 & 9 & 7 & $25(50,0)$ \\
\hline $\begin{array}{c}\text { Swab arrasto } \\
(\mathrm{n}=3)\end{array}$ & $\begin{array}{c}\text { Granja } \\
\text { (terminação) }\end{array}$ & 0 & 0 & 0 & 0 \\
\hline Ração (n=3) & $\begin{array}{c}\text { Granja } \\
\text { (terminação) }\end{array}$ & 1 & 1 & 0 & $2(4,0)$ \\
\hline $\begin{array}{l}\text { Fezes-Swab } \\
\text { retal }(\mathrm{n}=45)\end{array}$ & $\begin{array}{l}\text { Pocilga } \\
\text { de espera }\end{array}$ & 7 & 8 & 7 & $22(44,0)$ \\
\hline $\begin{array}{c}\text { Swab arrasto } \\
(\mathrm{n}=3)\end{array}$ & $\begin{array}{l}\text { Pocilga } \\
\text { de espera }\end{array}$ & 0 & 0 & 1 & $1(2,0)$ \\
\hline TOTAL & & $17(34,0)$ & $18(36,0)$ & $15(30,0)$ & $50(100)$ \\
\hline
\end{tabular}

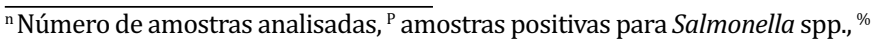
porcentagem de amostras positivas por amostra em relação ao total isolado.

A sorotipificação com antissoro 0 confirmou os 50 isolados como Salmonella spp. A análise com os antisoros B, C e $\mathrm{D}$ apresentou resultados concordantes com os obtidos na identificação oficial realizada no Laboratório de Enterobactérias da FIOCRUZ (Quadro 2).

Não houve aumento significativo (Quadro 3) nos isolamentos de Salmonella spp. após o transporte dos animais,

Quadro 2. Resultados da sorologia preliminar e da identificação oficial de Salmonella sp. isolados das amostras ambientais e de fezes de suínos

\begin{tabular}{|c|c|c|c|}
\hline \multicolumn{2}{|c|}{ Sorologia preliminar } & \multicolumn{2}{|c|}{ Caracterização Antigênica } \\
\hline Sorogrupo & $\mathrm{N}(\%)$ & Sorovar & $\mathrm{N}(\%)$ \\
\hline $\mathrm{B}$ & $28(56,0)$ & S. Typhimurium & $13(26,0)$ \\
\hline & & S. Agona & $15(30,0)$ \\
\hline $\mathrm{C}$ & $9(18,0)$ & S. Infantis & $9(18,0)$ \\
\hline D & $1(2,0)$ & S. Panama & $1(2,0)$ \\
\hline Salmonella spp & $12(24,0)$ & S. Minnesota & $12(24,0)$ \\
\hline
\end{tabular}

$\overline{\mathrm{N}(\%)}$ número de amostras positivas de cada sorovar e porcentagem em relação a o total de cepas de Salmonella spp.

indicando que o transporte não influenciou na porcentagem de isolamento $(\mathrm{p}=0,6625$ e $\mathrm{p}=0,5403)$. 0 decréscimo no número de excretores de Salmonella spp. observado nas fezes ao abate, não deve minimizar a importância dos animais provenientes de lotes positivos que chegam ao frigorífico. Estudos realizados anteriormente (Rostagno et al. 2003) demonstraram a importância da contaminação cruzada de animais negativos que chegam ao frigorífico, a partir de animais portadores que estão excretando Salmonella spp. nas fezes.
Quadro 3. Comparação do isolamento de Salmonella sp. das fezes de suínos na granja de terminação com o isolamento da bactéria nas fezes dos mesmos animais, na etapa de pré-abate no frigorífico pelo teste de McNemar

\begin{tabular}{cccc}
\hline $\begin{array}{c}\text { Frigorífico } \\
\text { Granja }\end{array}$ & Positivos & Negativos & Total \\
\hline Positivos & 12 & 13 & 25 \\
Negativos & 10 & 10 & 20 \\
TOTAL & 22 & 23 & 45
\end{tabular}

O Quadro 4 demonstra os sorovares identificados separadamente por suíno analisado. S. Agona foi o sorovar mais frequente, seguido por $S$. Typhimurium. Todos os sorovares foram isolados tanto na granja quanto no frigorífico, com exceção de $S$. Panama que não foi encontrada em amostras de fezes coletadas na granja de terminação (Quadro 5).

A diversidade de sorovares identificados em fezes suínas também foi observada em outros estudos. Bessa, Costa \& Cardoso (2004), no Rio Grande do Sul, identificaram 26 sorovares diferentes em 226 isolados de 300 suínos abatidos em três frigoríficos. Os sorovares mais prevalentes foram: Typhimurium (24,3\%), Agona (19,9\%), Derby $(13,2 \%)$ e Bredeney (12\%). S. Panama e S. Infantis também foram identificados, porém com menor freqüência $(5,75 \%$ e $0,88 \%$, respectivamente). Weiss et al. (2002) encontraram oito diferentes sorovares de Salmonella em amostras de fezes coletadas por swab retal. As amostras foram colhidas na granja de terminação e num frigorífico no Rio Grande do Sul. Os sorovares identificados foram Agona, Bredeney, Lexington, London, Mabandaka, Panama e Schwartzengrund.

Os sorovares Typhimurium, Agona e Infantis foram os mais isolados neste estudo. De acordo com Weiss et al. (2002) e Loureiro et al. (2010), estes sorovares são os mais associados a casos de salmonelose humana no Brasil. 0 alto índice de $S$. Agona atenta para o risco relacionado à doença clínica, junto a $S$. Derby, que têm aumentado significativamente, principalmente nos Estados Unidos (Oliveira \& Carvalho 2003). Também, S. Typhimurium, o segundo sorovar mais isolado, tem sido relatado em casos de enterocolite no rebanho, já que este sorovar juntamente com $S$. Cholerasuis são os mais incriminados em doença clínica (Hurd et al. 2001). Porém, durante as coletas não foi observada ou relatada pelos criadores sintomas de salmonelose nos animais em terminação.

De forma geral, a incidência de um mesmo sorovar pôde ser associada ao lote. Somente os sorovares S. Agona e $S$. Infantis foram detectadas em lotes diferentes sugerindo possível negligência a normas de biosseguridade, que pode contribuir para a manutenção do microrganismo no ambiente. Assim, é possível que os animais amostrados já estivessem infectados com esses sorovares em etapas de criação anteriores como desmame e creche. Esta hipótese concorda com Muller et al. (2009), que relataram que as fontes mais importantes de contaminação por Salmonella na produção de suínos são o alojamento de animais portadores que sofreram a infecção na fase de creche e a contaminação residual das instalações.

Das 33 amostras provenientes dos animais analisadas na primeira colheita, Salmonella spp. foi isolada em 17 
Quadro 4. Identificação antigênica dos sorovares de Salmonella por suíno amostrado, de acordo com o local de isolamento e com a coleta

\begin{tabular}{|c|c|c|c|c|c|c|c|c|}
\hline \multicolumn{3}{|c|}{ Primeira coleta } & \multicolumn{3}{|c|}{ Segunda coleta } & \multicolumn{3}{|c|}{ Terceira coleta } \\
\hline Animal & $\begin{array}{c}\text { Granja } \\
\text { Terminação }\end{array}$ & $\begin{array}{l}\text { Pocilga } \\
\text { Espera }\end{array}$ & Animal & $\begin{array}{c}\text { Granja } \\
\text { Terminação }\end{array}$ & $\begin{array}{l}\text { Pocilga } \\
\text { Espera }\end{array}$ & Animal & $\begin{array}{c}\text { Granja } \\
\text { Terminação }\end{array}$ & $\begin{array}{l}\text { Pocilga } \\
\text { Espera }\end{array}$ \\
\hline 1 & Typhimurium & $\mathrm{N}$ & 16 & Infantis & Infantis & 31 & $\mathrm{~N}$ & Minnesota \\
\hline 2 & $\mathrm{~N}$ & Typhimurium & 17 & $\mathrm{~N}$ & Infantis & 32 & $\mathrm{~N}$ & $\mathrm{~N}$ \\
\hline 3 & $\mathrm{~N}$ & $\mathrm{~N}$ & 18 & $\mathrm{~N}$ & $\mathrm{~N}$ & 33 & $\mathrm{~N}$ & Minnesota \\
\hline 4 & Typhimurium & $\mathrm{N}$ & 19 & $\mathrm{~N}$ & Agona & 34 & Minnesota & Minnesota \\
\hline 5 & Typhimurium & Typhimurium & 20 & Agona & Panama & 35 & $\mathrm{~N}$ & Infantis \\
\hline 6 & Typhimurium & $\mathrm{N}$ & 21 & Agona & Agona & 36 & Minnesota & Minnesota \\
\hline 7 & $\mathrm{~N}$ & Typhimurium & 22 & Infantis & $\mathrm{N}$ & 37 & Minnesota & $\mathrm{N}$ \\
\hline 8 & Typhimurium & Typhimurium & 23 & $\mathrm{~N}$ & $\mathrm{~N}$ & 38 & Minnesota & $\mathrm{N}$ \\
\hline 9 & $\mathrm{~N}$ & Agona & 24 & $\mathrm{~N}$ & Infantis & 39 & Infantis & $\mathrm{N}$ \\
\hline 10 & Agona & Agona & 25 & Agona & $\mathrm{N}$ & 40 & $\mathrm{~N}$ & $\mathrm{~N}$ \\
\hline 11 & $\mathrm{~N}$ & Typhimurium & 26 & Agona & Agona & 41 & $\mathrm{~N}$ & Infantis \\
\hline 12 & Agona & $\mathrm{N}$ & 27 & Agona & $\mathrm{N}$ & 42 & Minnesota & Minnesota \\
\hline 13 & Typhimurium & $\mathrm{N}$ & 28 & $\mathrm{~N}$ & $\mathrm{~N}$ & 43 & $\mathrm{~N}$ & $\mathrm{~N}$ \\
\hline 14 & Typhimurium & $\mathrm{N}$ & 29 & Agona & Agona & 44 & $\mathrm{~N}$ & $\mathrm{~N}$ \\
\hline 15 & $\mathrm{~N}$ & $\mathrm{~N}$ & 30 & Infantis & $\mathrm{N}$ & 45 & Minnesota & $\mathrm{N}$ \\
\hline
\end{tabular}

Quadro 5. Sorovares de Salmonella isolados em granja de terminação e pocilga de espera

\begin{tabular}{|c|c|c|c|}
\hline \multirow[t]{2}{*}{ Sorovar } & $\begin{array}{c}\text { Granja de } \\
\text { terminação }\end{array}$ & $\begin{array}{c}\text { Pocilga de espera } \\
\text { (frigorífico) }\end{array}$ & $\begin{array}{l}\text { Total } \\
N(\%)\end{array}$ \\
\hline & $\mathrm{N}(\%)$ & $\mathrm{N}(\%)$ & \\
\hline S. Typhimurium & $8(16,0)$ & $5(10,0)$ & $13(26,0)$ \\
\hline S. Agona & $9(18,0)$ & $6(12,0)$ & $15(30,0)$ \\
\hline S. Infantis & $4(8,0)$ & $5(10,0)$ & $9(18,0)$ \\
\hline S. Minnesota & $6(12,0)$ & $6(12,0)$ & $12(24,0)$ \\
\hline S. Panama & 0 & $1(2,0)$ & $1(2,0)$ \\
\hline TOTAL & $27(54,0)$ & $23(46,0)$ & $50(100)$ \\
\hline
\end{tabular}

N (\%) Número de amostras positivas de cada sorovar e porcentagem em relação ao total de amostras identificadas como Salmonella spp.

$(51,51 \%)$ ocasiões, sendo 16 provenientes das fezes e uma da ração. S. Typhimurium representou 76,47\% (13/17) dos isolamentos e $S$. Agona, 23,53\% (4/17) das cepas. Na segunda colheita, a positividade para Salmonella foi de $54,54 \%$ (18/33). Destas, 61,11\% (11/18) foram identificadas sorologicamente como S. Agona, 33,33\% (6/18) como S. Infantis e 5,56\% (1/18) como S. Panamá. Salmonella sp. foi isolada em $45,45 \%(15 / 33)$ amostras na terceira colheita, sendo $80,0 \%(12 / 15)$ identificadas sorologicamente como S. Minnesota e 20,0\% (3/15) como S. Infantis.

A homologia nos isolados de um mesmo sorovar foi comparada pelo coeficiente de similaridade de Dice e os dendograma estão ilustrados na Figura 1.

Foram discriminados dois grupos clonais diferentes em S. Typhimurium, ambos oriundos de animais do mesmo lote. 0 primeiro perfil é composto por clones presentes nas fezes dos animais quando estavam na granja e o segundo, no frigorífico. A similaridade de $88,5 \%$ entre os grupos denota uma alta proximidade genética, podendo ser originados de um mesmo ponto crítico. Dois isolados apresentaram perfil distinto, porém com similaridade maior que $75 \%$ com os demais (Fig.1A).

S. Agona apresentou um padrão diferenciado: ambos os grupos clonais apresentaram isolados de dois lotes diferentes e em fezes presentes tanto na granja quanto no frigorífico. A homologia de 78,7\% também indica baixa variabilidade gênica entre as estirpes (Fig.1B).
As altas porcentagens de similaridade encontradas nas amostras de ração para $S$. Typhimurium e $S$. Agona, $92,3 \%$ e $100 \%$ respectivamente, indicam que possivelmente esta foi a fonte primária que deu origem à infecção dos animais na granja (Fig.1A,B). A importância da ração como veículo de infecção para os suínos concorda com resultados de estudos de vários pesquisadores (Stärk et al. 2002, Lo Fo Wong et al. 2004, Kich et al. 2005, Silva et al. 2006).

S. Minnessota apresentou um grupo clonal com 10 estirpes, todos oriundos do terceiro lote. Dois isolados revelaram perfis distintos dos demais (Fig. 1C). A cepa isolada em $s w a b$ de arrasto da pocilga no frigorífico exibiu similaridade de $80 \%$ com o grupo principal. Portanto, é provável que a infecção anterior dos animais deu origem à contaminação do ambiente do frigorífico.

A maior similaridade foi observada para $S$. Infantis, sendo todos os isolados classificados como clones (Fig. 1D). É possível que este sorovar tenha sua origem associada à contaminação ambiental ou à uma infecção dos animais em etapas anteriores à terminação, como o desmame e a creche, já que os isolados do segundo e terceiro lote pertencem ao mesmo grupo clonal. Esta analogia entre isolamento em amostra ambiental e nos animais deve ser analisada levando-se em consideração que somente uma amostra foi coletada, podendo não refletir com segurança a ausência do microrganismo no ambiente.

O baixo isolamento de S. Panama indica que provavelmente está presente no ambiente do frigorífico, porém em baixos números, de forma que só foi recuperada em uma amostra.

Deve-se considerar a importância da contaminação cruzada entre os animais. De acordo com Hurd et al. (2001), a presença de um suíno infectado caracteriza uma possível fonte de transmissão para os demais que adquirem o microrganismo durante o transporte ao frigorífico ou mesmo nas baias de descanso, indicando risco de contaminação das carcaças e, consequentemente, do produto final. 

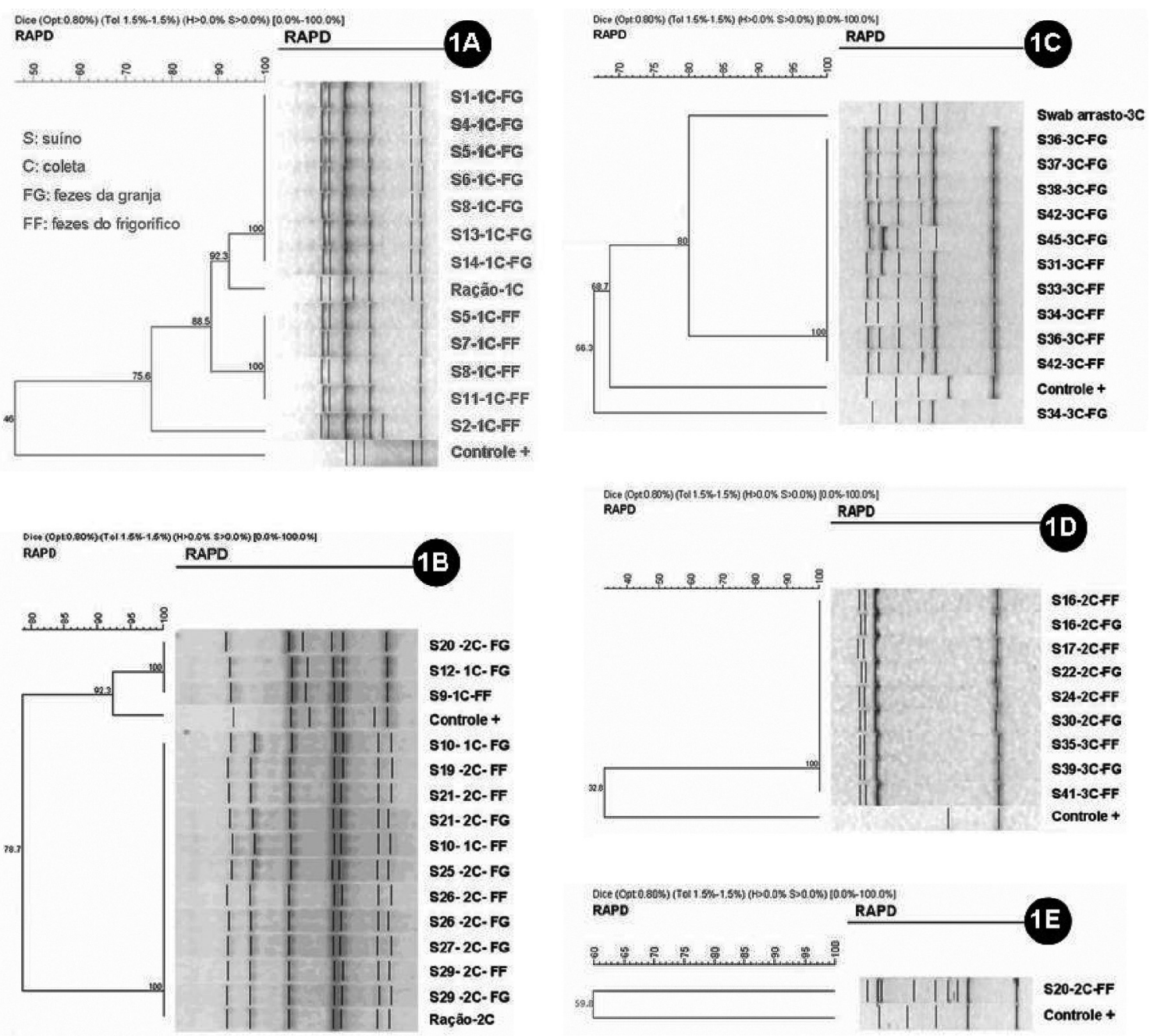

Fig.1. Dendrogramas dos 50 isolados de Salmonella discriminados por sorovar. (1A) Isolados de S. Typhimurium. (1B) S. Agona. (1C) S. Minnesota. (1D) S. Infantis. (1E) S. Panama. (S) suíno, (C) coleta, (FG) isolados de fezes dos animais na granja, (FF) isolados de fezes dos animais no frigorífico.

\section{CONCLUSÕES}

A análise filogenética denotou a influência de diferentes fatores, como a contaminação cruzada entre os suínos e o ambiente e a ração contaminada, na existência e permanência de Salmonella spp. nos animais.

A diversidade de espécies e as diferentes fontes de infecção identificadas no presente estudo reforçam a importância de um monitoramento rigoroso que permita a promoção de controles adequados de Salmonella spp. no processo produtivo de suínos.

Agradecimentos.- À Fundação de Amparo à Pesquisa do Estado de Minas Gerais (Fapemig) pelo financiamento deste estudo.

\section{REFERÊNCIAS}

Ayres M. 2000. Aplicações Estatísticas nas Áreas das Ciências Biológicas e Médicas. Sociedade Civil Mamirauá, Belém. 272p.

Bessa C.M., Costa M. \& Cardoso M. 2004. Prevalência de Sal monella sp em suínos abatidos em frigoríficos do Rio Grande do Sul. Pesq. Vet. Bras. 24:2:80-84.

Brasil 1994. Secretaria de Defesa Agropecuária. Portaria Ministerial no 193, de 19 de Setembro de 1994. Programa Nacional de Sanidade Avícola (PNSA). Disponível em <http://extranet.agricultura.gov.br/sislegis-consulta> Acessado em 25 out. 2010.
Castagna S.M.F., Schwarz C.W. \& Cardoso M. 2004. Presença de Salmonella sp. no trato intestinal e em tonsilas/linfonodos submandibulares de suínos ao abate. Arq. Bras. Med. Vet. Zootec. 56(3):300-306.

European Food Safety Authority 2008. Report of the Task Force on Zoonoses Data Collection on the Analysis of the Baseline Survey on the Prevalence of Salmonella in Slaughter Pigs. Part A. Salmonella prevalence estimates. EFSA J. 111p.

European Food Safety Authority 200 9. The Community Summary Report on Trends and Sources of Zoonoses and Zoonotic Agents in the European Union in 2007. EFSA J. 223p.

European Food Safety Authority. 2010. Analysis of the baseline survey on the prevalence of Campylobacter in broiler batches and of Campylobacter and Salmonella on broiler carcasses in the EU, 2008. EFSA J. 8(3). 1503p.

Fedorka-Cray P.J. 1996. The connection between Salmonella, swine, and food safety. In: Proc. Swine Conference, Lincoln, Nebrasca, p.25-45.

Hill A.A., Snary E.L., Arnold M.E., Alban L. \& Cook A. J. 2008. Dynamics of Salmonella transmission on British pig grower-finisher farm: A stochastic model. Epidemiol. Infect. 136(3):320-333.

Hurd H.S., Gailey J.K., McKean J.D. \& Rostagno M.H. 2001. Rapid infection in market-weight swine following exposure to a Salmonella Typhimurium-contamined environment. Am. J. Vet. Res., 62:8:1194-1197.

Katja R. \& Henrik J.A. 2003. Factors of significance for pork quality: A review. Meat Sci. 64:219-237. 
Kich J.D., Mores N., Piffer I.A., Coldebella A., Amaral A., Ramminger L. \& Cardoso M. 2005. Fatores associados à soroprevalência de Salmonella em rebanhos comerciais suínos. Ciencia Rural 35(2):398-405.

Lo Fo Wong D.M.A., Dahl J., Wingstrand A., Van der Wolf P.J., Von Altrock A. \& Thorberg B.M. 2004. A European longitudinal study in Salmonella seronegative and seropositive-classified finishing pig herds. Epidemiol. Infect. 132(5):903-914.

Loureiro E.C.B., Marques N.D.B., Ramos F.L.P., Reis E.M.F., Rodrigues D.P. \& Hofer E. 2010. Salmonella serovars of human origin identified in Pará State, Brazil from 1991 to 2008. Revta Pan-Amaz. Saude 11:93-100.

Michael G., Simoneti R., Costa M. \& Cardoso M. 2003. Comparison of different selective enrichment steps to isolate Salmonella sp. from feces of finishing swine. Braz. J. Microbiol. 34:138-142.

Muller M., Schwarz P., Kich J.D. \& Cardoso M. 2009. Perfil sorológico e de isolamento de Salmonella sp. em suínos no início da terminação e ao abate. Ciênc. Anim. Bras. 10(3):931-937.

Oliveira C.J.B. \& Carvalho L.F.O.S. 2003. Infecções por Salmonella em suínos: panorama e perspectivas. Suinoc. Ind. 3:35-39.

Oliveira F.A., Frazzon A.P.G., Brandelli A. \& Tondo E.C. 2007. Use of PCR- ribotyping, RAPD, and antimicrobial resistance for typing of Salmonella enteritidis involved in food-borne outbreaks in Southern Brazil. J. Infect. Develop. Count. 1(2):170-176.

Rostagno M.H., Hurd H.S., McKean J.D., Ziemer C.J., Gailey J.K. \& Leite R.C. 2003. Preslaughter holding environment in pork plants is highly contaminated with Salmonella enteric. Appl. Environ. Microbiol. 69:4489-4494.

Silva L.E., Gotardi C.P., Vizzotto R., Kich J.D. \& Cardoso M.R.I. 2006. Infecção por Salmonella sp. em um sistema integrado de produção de suínos. Arq. Bras. Med. Vet. Zootec. 58(4):455-461.

Stärk K.D.C., Wingstrand A., Dahl J., Mogelmosea V. \& Lo Fo Wong D.M. 2002. Differences and similarities among experts' opinions on Salmonella enteric dynamics in swine pre-harvest. Prev. Vet. Med. 53:7-20.

Van der Gaag M.A., Vos F., Saatkamp H.W., Van Boven M., Van Beek P. \& Huirne R.B.M. 2004. A state-transition simulation model for the spread of Salmonella in the pork supply chain. Cent. Eur. J. Oper. Res., Amsterdam, 156:782-798.

Weiss L.H.N., Nonig R.B. Cardoso M. \& Costa M. 2002. Ocorrência de Salmonella spp. em suínos de terminação no Rio Grande do Sul. Pesq. Vet. Bras. 22:104-108. 